by the State in providing educational facilities for these leaders of men is a profitable investment.

At present, the Government grant to meet expenditure in respect of elementary education is about II,500,00ol. annually; and the sum paid in grants for pupils in secondary schools in England and Wales taking an approved course between the ages of twelve and sixteen vears is about $340,000 l$. In addition, local authorities expend about 3,400,oool. a year on education othe: than elementary. Of this amount, about $700,000 l$. is expended on secondary schocls, 1,200,00ol. on evening schools and institutions for higher and technical education and 260,00ol. upon day schools of similar scope. The State-aid and rate-aid to the seven hundred secondary schools, now accommodating about II3,000 pupils in England and Wales, amounts, therefore, to rather more than one million pounds annually.

This is a modest sum compared with expenditure upon other objects, but little increase can be justified for secondary schools until the demand for secondary education is greater and more real than at present. Free education from the primary school to the university may be within the realm of practical politics, but unless it is accompanied by maintenance zrants equivalent to the wage-earning capacities of poor students it will not satisfy the demands of the Trade Unionists. Whether it is desirable to offer this inducement to continued study to all children may be doubted; the nation should be concerned only in providing adequate opportunities for the development of children whose life-work is likely to promote national welfare. The way should be open from the primary school to the university, but a passport should be demanded at each gate to show that the student is capable of making the best use of the new fields to which he is admitted. By this system, and a judicious extension of the number of intermediate and senior scholarships to provide for maintenance, any student of distinguished ability would be able to command the highest educational training this country can offer.

R. A. G.

\section{RADIUM INSTITUTES}

THE March number of the Deutsche Revuc is to contain the announcement by Prof. P. Lenard, director of the Physikalische Institut of the Lniversity of Heidelberg, that a radium institute, of the kind already in process of formation in Vienna, London, and Berlin, is to be opened for work in Heidelberg in the Easter of the present year. Owing to the foresight and cooperation of the Senate of the University and the Ministry of the Grand Duchy of Baden, an endowment has been secured, and the Heidelberg Institute will thus be the first of its kind actually to come into existence and to commence work. It is to be known as the Radiologische Institut. The term Radiology, which we might also with advantage accept, is used in Germany to connote the newer branches of physics concerned with the study of the invisible radiations, particularly, of course, the kathode, Lenard, Röntgen, and Becquerel rays, but comprising also the older known invisible ultra-violet and infra-red light radiations, their methods of production, their relations to matter, including radio-activity, phosphoresence, and photoelectric action, and their practical applications, for example, in medicine.

Prof. Lenard prefaces his announcement with the remark that the new field of investigation has already proved itself of such fruitfulness that it is quite

1 Published by Richard Fleischer, of the Deutsche Verlags Anstalt. impossible at the present time to delimit its true circumference. Every day arise new problems, for example, in such fundamental subjects as the constitution of matter, now assailable with hope of success. The cultivation of this field demands special foster. ing, not only on account of its immediate fruitfulness, but also on account of the costliness of its prosecution-if only in the provision of those rare materials, like radium, which it has brought into recognitionand on account of the necessity for close cooperation between the scientific workers and those engaged in the practical applications of the new knowledge.

The new institute at Heidelberg is to undertake this work. It is to be under the same direction as the Physikalische Institut of the University, and will thus secure full benefit from the whole existing resources of the institute. Provisionally 300 square metres area in the Frederichsbau will be set aside for it. Later it will be housed in a special wing of the new buildings of the Physical Institute. The endowment will ensure the furnishing of the institute with the best equipment that can be secured, while the spring sediments from the neighbouring State of Kreuznach, to be worked up by the Government salt department, will provide a source of radio-active material for clinical and scientific investigation. The institute will provide special instruction in the subjects it deals with, while the clinical work will be undertaken by Herren Czerny and Krehl in their own buildings, but with close cooperation with the Physical Institute, which will ensure that the work rests upon a thoroughly sound scientific basis.

The constitution and work of the Radium Institute to be established in London are described in an official statement published in the British Medical Journal of March 6 . From this statement we learn that the King has consented to become the patron of the institute. A site has been acquired in Riding House Street, Portland Place, upon which the necessary building will be erected with as little delay as possible. In general terms, it may be said that the institute will be conducted upon the lines of the Radium Institute in Paris. In addition to the superintendent, the assistant to the superintendent, and the director of the laboratory, there will be an honorary medical and surgical staff (not yet appointed). The institute hopes to acquire radium to the amount of 5 grams.

The treatment carried out in the institute will be strictly limited to treatment by radium or other radio-active substances. Treatment of cases by the Röntgen rays, the Finsen light, and by electrical currents will have no place in the institute, as such measures of treatment are already very amply provided for elsewhere.

The building will be in two parts, with separate entrances. One section will be devoted to necessitous patients, and the other to the well-to-do. The former will be treated free; the latter will be required to pay fees on such a scale as the medical and surgical staff may determine. No patient, poor or well-to-do, will be treated in the institute except upon the imprimatur of a qualified medical man.

Demonstrations in the use of radium will be given, and medical practitioners can be advised as to the mode of employment and as to the radio-activity of their own specimens of radium.

\section{THE SUMMER SEASON TIME BILL.}

THE uebate upon the Summer Season Time Bill, commonly known as the Daylight Saving Bill, in the House of Commons on Friday last, was, for the most part, a pitiful exhibition of the incompetence of politicians to understand any question involving a knowledge of elementary science. I hough the proposals in the Bill would dislocate the entire machinery of time-reckoning, less than forty members were present at the opening of the discussion; and

NO. 2054, VOL. 80] 